\title{
Produção de Arroz e Alteração da Paisagem: um Estudo de Caso em Capané, Cachoeira do Sul/RS

\author{
Rice Production and Landscape Change: \\ a Case Study in Capané, Cachoeira do Sul/RS
}

\author{
Jonas Milanesi $\mathrm{i}^{\mathrm{i}}$ \\ Pontifícia Universidade Católica (PUC-RS) \\ Porto Alegre, Brasil \\ Tânia Rodrigues Ferrer ii \\ Pontifícia Universidade Católica (PUC-RS) \\ Porto Alegre, Brasil
}

\begin{abstract}
Resumo: Na região central e fronteira oeste do estado do Rio Grande do Sul são frequentes as alterações da paisagem influenciadas pelo cultivo do arroz. Neste contexto, o objetivo do presente artigo é investigar como o cultivo de arroz interferiu na paisagem do município de Cachoeira do Sul/RS nos anos de 1975 até 2015. Para isso, realizou-se a coleta de dados a partir do levantamento do contexto histórico, analisando as ações humanas, numa perspectiva temporal e espacial. Para tal, utilizou-se técnicas de Sensoriamento Remoto e Geoprocessamento, concomitantemente à análise perceptiva da paisagem na área de estudo. Dentre os resultados alcançados, no que diz respeito à produção do arroz, o cenário agroeconômico interfere diretamente em tais mudanças. Por mais que a cultura do arroz esteja consolidada no referido local de estudo, foi possível perceber a existência de locais com potencial de expansão agrícola. No entanto, considerando o contexto histórico e os resultados que foram levantados, pode-se dizer que tal expansão ocorrerá paulatinamente na paisagem local.
\end{abstract}

Palavras-chaves: Espaço Geográfico; Paisagem Natural e Construída; Sensoriamento Remoto e Geoprocessamento; Cultura Orizícola; Cachoeira do Sul/RS.

Abstract: Rice cultivation often is responsible for landscape change in central and western Rio Grande do Sul State. This article investigates how rice cultivation transformed the landscape in the municipality of Cachoeira do Sul from 1975 to 2015. Data was collected concerning temporal and spatial human action and analyzed using remote

\footnotetext{
' Geógrafo - PUC-RS; Pesquisador do Grupo Geomática Aplicada à Educação e Aplicação de Técnicas de Sensoriamento Remoto em Estudos Ambientais da PUC-RS. jonasmilanesi@gmail.com

ii Professora Adjunta. tania.ferrer@pucrs.br
} 
sensing and geoprocessing methods. Results are presented showing how rice production interfered directly in land use change and areas with the potential for further expansion were identified. However, agricultural expansion occurred slowly over time so that the local landscape will change gradually in the future.

Keywords: Geographic Space; Natural and Constructed Landscapes; Remote Sensing and Geoprocessing; Rice Farming; Cachoeira do Sul/RS.

\section{Introdução}

O meio técnico científico traz avanços aos mais variados setores e na agroindústria acaba por otimizar as áreas de plantio e aumentar o rendimento das safras. No entanto, mesmo com o uso da tecnologia, ainda grandes áreas são ocupadas para o plantio de diferentes culturas, o que provoca impactos e transformações na paisagem. Neste contexto, o município de Cachoeira do Sul está situado na segunda maior região produtora de arroz do estado do Rio Grande do Sul, a região da Depressão Central, perdendo somente para região da Fronteira Oeste, maior produtora da cultura.

Diante disso, o presente trabalho procura investigar como o cultivo de arroz interferiu na paisagem de Cachoeira do Sul nos anos de 1975 e 2015, sendo necessário realizar uma revisão de conceitos geográficos, dividindo-se nas seguintes etapas de trabalho: espaço geográfico, as diferentes formas que integram a paisagem, o uso do sensoriamento remoto e do geoprocessamento em áreas agrícolas; caracterizar o processo geo-histórico de transformação da paisagem através das técnicas de sensoriamento remoto e geoprocessamento; analisando como a paisagem da área de estudo sofreu interferência pelo cultivo do arroz.

A coleta de dados ocorreu através do levantamento do contexto histórico, analisando as ações humanas, numa perspectiva temporal e espacial. Para tal, utilizou-se técnicas de sensoriamento remoto e geoprocessamento, concomitantemente à análise perceptiva da paisagem da área de estudo, considerando a interferência do cultivo do arroz ao longo desses 40 anos.

\section{Contexto Geo-Histórico de Cachoeira do Sul/RS}

Cachoeira do Sul é uma cidade que está situada na região Centro Oriental Rio-Grandense. Possui uma população de 83.294 habitantes, segundo o censo de 2010 realizado pelo Instituto Brasileiro de Geografia e Estatística (IBGE). A área de estudo compreende a microbacia do arroio S.D.E , tributário do Arroio Capané, situado na localidade do Capané. Segundo os resultados obtidos pelo modelo hidrológico do estudo, a microbacia apresenta uma área de 64,73 km² (Figura 1). 


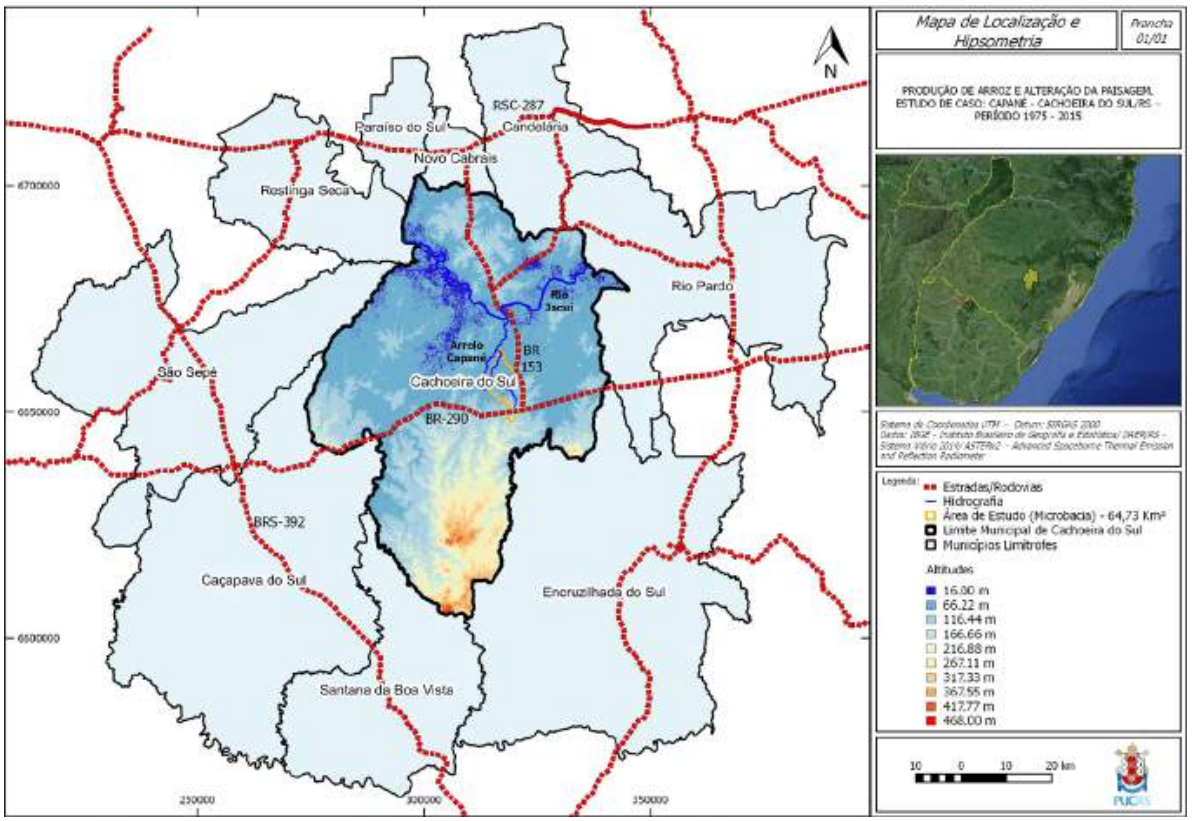

Figura 1 - Mapa de Localização e Hipsometria de Cachoeira do Sul/RS.

Quanto aos aspectos físicos, o município está situado na região da Depressão Central do Estado do Rio Grande do Sul e possui distintas disposições em seu relevo, predominantemente áreas de planície.

Ao analisar a Carta do Exército de Cachoeira do Sul (Folha MI-2984/1), tratando-se dos cursos de água de grande e pequeno porte, além do Rio Jacuí, existem outros rios importantes, sendo eles: o Rio Botucaraí, Rio Vacacaí, Rio Santa Bárbara, Arroio Irapuá, Arroio Capané, entre outros. Nessa perspectiva, fica evidente quão privilegiada é a região no que diz respeito ao abastecimento de água de diversos rios e por estar inserida na região dos depósitos sedimentares (RADAMBRASIL, 1986). O uso da água se destina principalmente para a irrigação de plantações, sobretudo, as lavouras de arroz. Estas necessitam de uma irrigação realizada pelo método de inundação, tornando excessivo o uso de água (IRGA, 2012).

A precipitação média anual de Cachoeira do Sul/RS fica entre 1600 a 1700 milímetros (SEPLAN, 2004). O regime de precipitações nesta região é essencial para manter os níveis dos rios estáveis e, consequentemente, nutrir o abastecimento de água nas lavouras de arroz, já que o método de irrigação se dá por inundação (IRGA, 2012).

Segundo os dados disponibilizados pela Fundação de Economia e Estatística (FEE), no período de 1995 a 2013, foi possível observar um decréscimo nos últimos anos das áreas (em hectares) de arroz plantadas em Cachoeira do Sul, como exposto na Figura 2. 


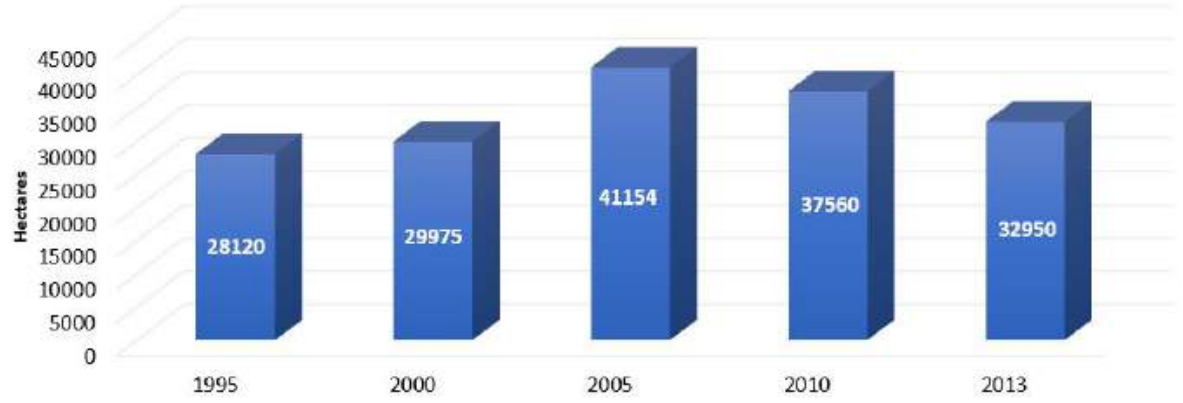

Figura 2 - Área Plantada de Arroz em Cachoeira do Sul/RS no Período de 1995 a 2013. Modificado de: FEE (2015).

Segundo Stefano (2009), no período de 1975 a 2005, o Brasil reduziu sua área de plantio em torno de $26 \%$ e, mesmo assim, aumentou sua produção de arroz em $69 \%$, devido ao aumento de $128 \%$ na produtividade média. Essa produção permitiu ao país tornar-se autossuficiente em arroz na safra de 2003.

Atualmente, há cada vez mais a busca pelo aumento da produtividade e a abordagem técnica e científica vem proporcionando diferentes avanços para os mais diversos setores da agroindústria. Para o arroz, o desenvolvimento e a adaptação das sementes foram um marco para o aumento da produtividade nas lavouras. Em 1995 o Instituto Rio Grandense do Arroz (Irga) desenvolveu a variedade Irga 417, consolidando o arroz gaúcho como top de qualidade no país (COSTA, 2012).

$\mathrm{Na}$ cultura orizícola, tal abordagem otimizou/diminuiu as áreas de plantio, aumentando o rendimento das safras. Segundo os dados da Fundação de Economia e Estatística (FEE) de 2015 foi constatado um crescimento no valor da produção de arroz no período de 1995 a 2013, diferentemente das áreas de plantio que, em 2013, diminuíram (Figura 3).

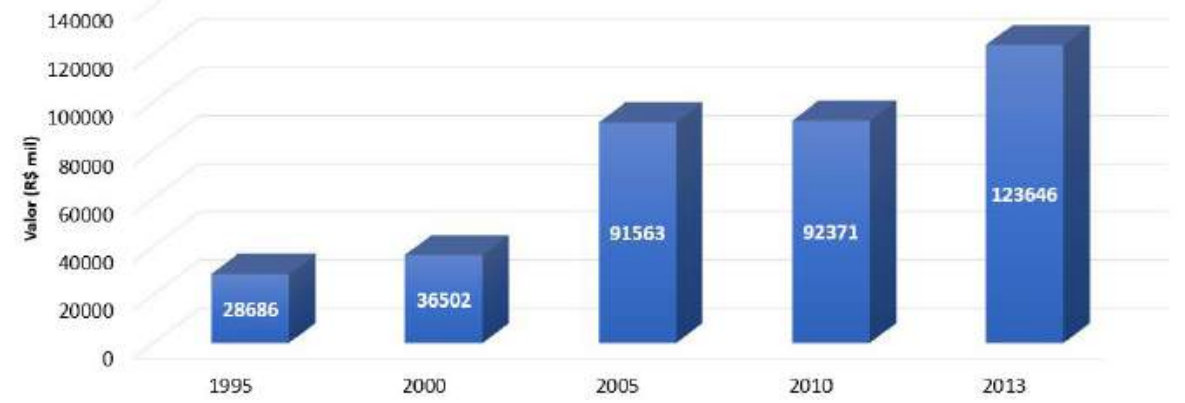

Figura 3 - Valor da Produção de Arroz em Cachoeira do Sul no Período de 1995 a 2013. Modificado de: FEE (2015). 
Cachoeira do Sul/RS é conhecida atualmente como a Capital Nacional do Arroz, pois em 1941 ocorreu uma colheita excepcional, vindo a motivar os produtores e autoridades a realizarem uma grande festa regional: a Fearroz (RITZEL, 1997). A partir de 1968, a festa foi reeditada, por obter um reconhecimento nacional, e foi denominada como Fenarroz - Festa Nacional do Arroz, criando um parque especialmente para o evento, que hoje ocorre a cada três anos (RITZEL, 1997). Cachoeira do Sul recebe o título de Capital Nacional do Arroz, não só pelo nível de produção excelente, mas também por ser a primeira que iniciou a produção com irrigação mecanizada nas lavouras (RITZEL, 1997).

\section{Referencial Teórico}

Em momentos históricos distintos do nosso planeta, desde as origens da estruturação, com suas características físicas geográficas, até mesmo, a complexidade das relações que envolvem o mundo global em que vivemos na atualidade, a geografia detém-se continuamente a compreender as transformações, tendo o espaço geográfico como objeto de estudo. Segundo Ab'Sáber (2002), o entendimento de espaço geográfico condiz com o conceito trazido por Santos (2006), partindo do princípio de compreender o espaço de um modo total na relação entre natureza e homem. Para Ab’Sáber (2002), o espaço total é definido como um

[...] arranjo e perfil adquiridos por uma determinada área em função da organização humana que lhe foi imposta ao longo dos tempos. Nesse sentido, pressupõe a um entendimento - na conjuntura do presente - de todas as implantações cumulativas realizadas por ações, construções e atividades antrópicas. A gênese do espaço - considerado de um modo total - envolve uma análise da estruturação espacial realizadas por ações humanas sobre os atributos remanescentes de um espaço herdado da natureza. Por essa razão, há que conhecer o funcionamento dos fluxos vivos da natureza (perturbados, mas não inteiramente eliminados) e toda a história e formas de ocupação dos espaços criados pelos homens. (AB'SÁBER, 2002, p. 30).

Nessa perspectiva, compreende-se que o espaço total é a combinação dos remanescentes do meio natural, associados às atividades antrópicas de uma área, considerando seu contexto histórico.

Segundo Santos (2006, p. 39), o espaço geográfico é formado por um "conjunto indissociável, solidário e também contraditório, de sistemas de objetos e sistemas de ações, não considerados isoladamente, mas como o quadro único no qual a história se dá". O autor descreve que os sistemas de objetos e ações passam a transformar-se de acordo com cada período histórico. Santos (2006) alega que outrora a natureza era selvagem, formada por objetos naturais e, que ao longo do tempo, passaram a ser substituídos por objetos fabricados e/ou mecanizados. Cada sistema de objetos e ações estará relacionado a um determinado momento histórico, pois "cada lugar geográfico concreto corresponde, em cada momento, um conjunto de técnicas e de instrumentos de trabalho, 
resultado de uma combinação específica que também é historicamente determinada" (SANTOS, 2006, p.35). Desta forma, compreende-se que os

[...] sistemas de objetos e sistemas de ações interagem. De um lado, os sistemas de objetos condicionam a forma como se dão as ações e, de outro lado, o sistema de ações leva à criação de objetos novos ou se realiza sobre objetos preexistentes. É assim que o espaço encontra a sua dinâmica e se transforma (SANTOS, 2006, p. 39).

Ao fazer referência ao conceito de espaço geográfico, pode-se considerar essencialmente a ligação entre natureza e sociedade. A fim de compreender o cenário complexo que é o espaço geográfico, cabe ao geógrafo analisar diferentes categorias do espaço para melhor reproduzir uma compreensão sobre o meio, utilizando diferentes escalas, entre elas, território, região, paisagem e lugar. É apontado por Santos (2006) que, na realização de uma análise, compete ao geógrafo levar em conta todos os objetos existentes numa extensão contínua, sem exceções, caso contrário, cada objeto não faria sentido.

Santos, além de trabalhar com o conceito de espaço, traz a definição de paisagem como "apenas a porção da configuração territorial que é possível abarcar com a visão" (SANTOS, 2006, p. 67). No entanto, não se restringe somente ao visual, pois é na paisagem que se manifestam as heranças de relações entre homem e natureza (SANTOS, 2006).

Neste contexto, pode-se dizer que cada porção do espaço geográfico está relacionada intrinsecamente a um processo de produção, podendo sofrer influência direta ou indiretamente numa determinada região, sendo ela o espaço urbano ou rural. As modificações que envolvem a paisagem podem ocorrer de duas formas. Uma delas, natural, envolve ações e/ou fenômenos da natureza, como a influência dos ventos, terremotos, atividades vulcânicas, precipitações, dentre outros. Outra forma é a antrópica, referente à influência do homem sobre o meio, causando variadas transformações no ambiente, como as áreas de usos agrícolas, reflorestamentos, estradas, barragens, entre outros.

As modificações no espaço geográfico podem ser compreendidas através da capacidade racional de um indivíduo poder ler a paisagem e ao mesmo tempo diferenciá-la de outra. Parece simples, mas nem sempre é tão fácil fazer esta diferenciação. Segundo Verdum (2012), a paisagem natural é composta pela interação dos elementos naturais, como o relevo, vegetação, solo, rios, entre outros. Já a paisagem construída tem influência da ação antrópica, por exemplo, edificações, estradas, barragens, áreas de plantio etc.

De acordo com Santos (1994), a paisagem construída ou paisagem artificial, como é chamada pelo autor, é "a paisagem transformada pelo homem, enquanto grosseiramente podemos dizer que a paisagem natural é aquela ainda não mudada pelo esforço humano". (SANTOS, 1994, p. 64). Nem sempre há uma diferença notável entre a paisagem natural e construída, o que pode tornar difícil a compreensão do espaço analisado. A geografia como ciência contempla compreender a (re)organização do espaço geográfico com as relações que nele ocorrem. Cabe ao geógrafo interpretar estas relações e o uso das técnicas de geoprocessamento auxilia a construção deste conhecimento.

Neste sentido, o geoprocessamento contempla um conjunto de técnicas e ferramentas que são conhecidos como Sistemas de Informações Geográficas (SIGs). Tais ferramen- 
tas computacionais, permitem realizar análises complexas, ao integrar dados de diversas fontes e ao criar bancos de dados georreferenciados, sendo aqui empregadas na análise do espaço geográfico.

Existem diferentes meios tecnológicos para aquisição de informações a serem manipuladas em um SIG, entre eles, o próprio sensoriamento remoto. Por meio de sensores aerotransportados em plataformas como, por exemplo, satélites, radares e aeronaves Remotamente Pilotadas (RPA - Remotely Piloted Aircraft), é possível obter-se imagens da superfície terrestre. O conceito de Sensoriamento Remoto faz uso do termo "sensores", "podendo ser entendido como dispositivos capazes de captar a energia refletida ou emitida por uma superfície qualquer e registrá-la na forma de dados digitais." (FITZ, 2008, pag. 97).

Diante da potencialidade das imagens de satélite, variados estudos podem ser realizados. Neste estudo, a utilização do sensoriamento remoto para definição das áreas naturais ocupadas pela cultura do arroz abrange objetos com alta correlação espacial, entendidos como: áreas com vegetação densa, campos, corpos de água e áreas de produção agrícola. Por meio do sensoriamento remoto foi possível estimar a área cultivada de arroz irrigado na imagem de satélite.

\section{Metodologia}

Para o reconhecimento das áreas que sofreram transformações no período estudado, utilizaram-se imagens de satélites e cartas topográficas. Para a identificação das áreas de cultivo do arroz, no ano de 1975, foi utilizada a Base Cartográfica do Exército Folha MI 2984-1 de Cachoeira do Sul e, nas cenas do ano de 2015, imagens de satélites. Também foram realizadas fotografias em campo com o propósito de enriquecer a análise.

Para as operações de geoprocessamento empregadas neste estudo, utilizaram-se os seguintes softwares: QGIS, certificado pela General Public License (GNU), para efetuar a integração das bases para elaboração dos mapas, cálculos, tratamento de imagens e delimitação das áreas plantadas de arroz; TerraHidro, desenvolvido pelo Instituto Nacional de Pesquisas Espaciais (INPE), para a extração da rede de drenagem e modelagem hidrológica, possibilitando a delimitação da microbacia do arroio (local estudado) e; Google Earth Pro, para visualizar e corroborar com as análises do estudo. Cabe salientar que o software TerraHidro é gratuito e que se trata de tecnologia nacional, que merece crédito.

Para a delimitação da área de estudo, foram levantadas as características físicas obtidas a partir do Modelo Digital de Elevação (MDE) como base de análise. Para a constituição do modelo, foram utilizados os dados altimétricos do sensor ASTER GDEM v2-Advanced Spaceborne Thermal Emission and Reflection Radiometer (ASTER) Global Digital Elevation Model (GDEM). Os dados do Sensor ASTER GDEM v2 referem-se a informações altimétricas mais atuais disponibilizadas gratuitamente pela National Aeronautics and Space Administration (NASA) no ano de 2011.

Este Modelo Digital de Elevação serviu como arquivo base para o software TerraHidro gerar a delimitação da área de estudo, ou seja, a microbacia hidrográfica (Figura 4). 


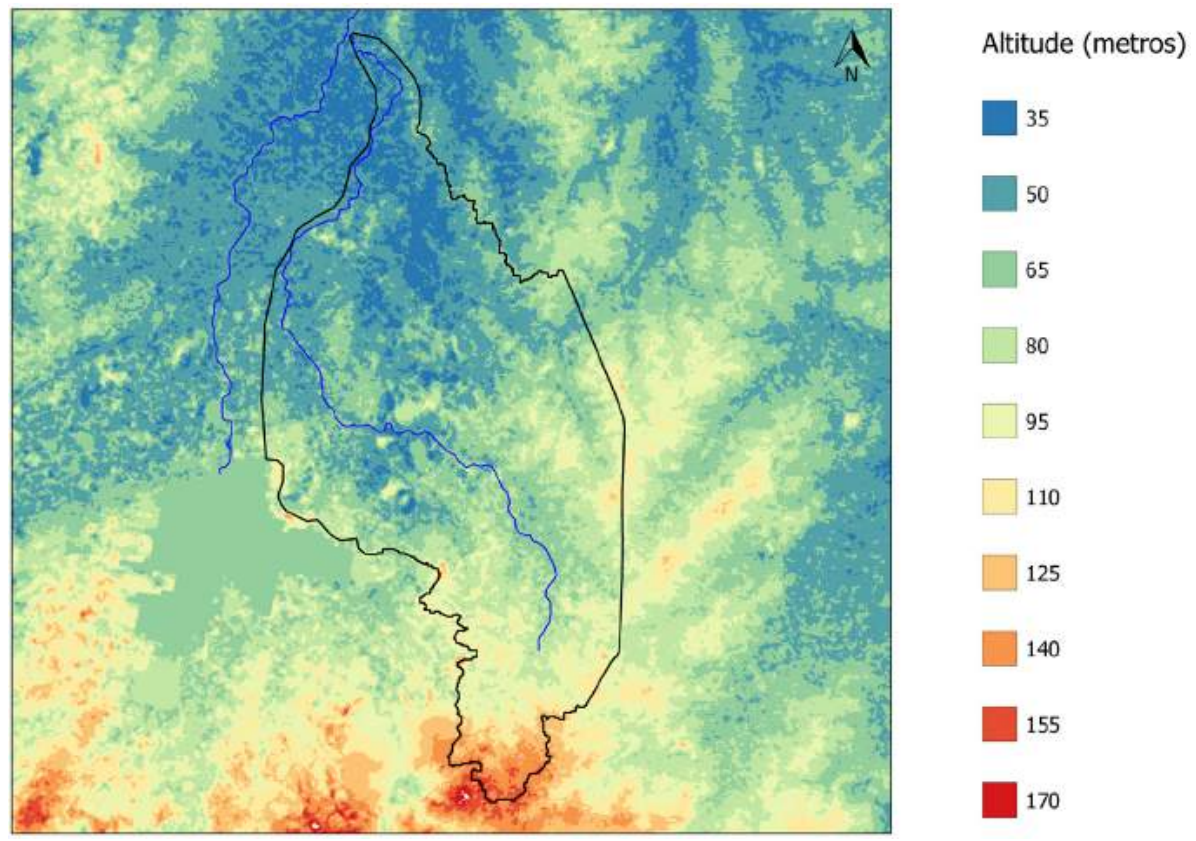

Figura 4 - Microbacia Hidrográfica Extraída Através da Altimetria do Sensor ASTER GDEM v2 (2011.)

A imagem do ano de 2015 para classificação supervisionada da cobertura e uso da terra, especificamente na identificação da cultura orizícola, foi obtida por meio do satélite Landsat-8, tendo o download sido feito no catálogo de imagens do site EarthExplorer da United States Geological Survey (USGS), Serviço Geológico dos Estados Unidos. As imagens espectrais do satélite Landsat- 8 consistem em nove bandas espectrais com uma resolução espacial de 30 metros para Bandas 1 a 7 e 9 (USGS, 2015). Em seguida, foi gerada uma imagem de cor natural, através das bandas espectrais 2 (Blue), 3 (Green) e 4 (Red).

No Estado do Rio Grande do Sul, o plantio ou semeadura do arroz, pode ocorrer em uma ampla faixa de meses, tendo início em setembro e indo até meados de dezembro (IRGA, 2012). Levando em consideração o período médio de dois meses para o desenvolvimento da planta, a data escolhida para a obtenção da imagem do satélite Landsat-8 foi o dia 20 de março de 2015, pois nos meses de janeiro e fevereiro teve a ocorrência de nuvens nas imagens, não sendo possível a visualização dos objetos, ou seja, as lavouras de arroz. Porém, observou-se na imagem escolhida correlação espacial que possibilitou a identificação das áreas de plantio de arroz. Para validar o resultado, além das informações altimétricas, utilizara-se as imagens de alta resolução disponíveis no software Google Earth Pro e os dados levantados durante a visita ao campo.

Em um segundo momento, realizou-se a classificação supervisionada das áreas de plantio de arroz do ano de 1975, através da Carta do Exército Folha MI - 2984-1 de Cachoeira do Sul. 


\section{Resultados e Discussões}

Na década de 1960, houve o aumento da lavoura mecanizada, principalmente no cultivo do arroz (TRT4, 2005). Este fato corrobora com Santos (2006), ao pensar o espaço geográfico como um sistema de objetos e ações em constante transformação ao longo de cada período histórico. Neste contexto, tal mecanização buscava a otimização da cultura, constituindo-se em objeto técnico na busca pela exatidão funcional, mais eficaz que os objetos naturais já presentes na paisagem. Pode-se dizer que o cenário histórico foi um dos determinantes nas alterações da paisagem da área de estudo em questão, a localidade do Capané.

Através da Carta do Exército Folha MI - 2984-1 de Cachoeira do Sul do ano de 1975, foi possível identificar um montante de 1.800,58 hectares de lavouras de arroz já existentes nesta época. Em um segundo momento, com a identificação e análise das áreas de plantio de arroz para o ano de 2015, foi identificado um total de 2.313,84 hectares, no qual se observa um acréscimo de 513,26 hectares de área ao longo destes 40 anos. Como parte dos resultados, foi possível a criação do mapa da ocupação das terras com cultivo de arroz em Capané (Figura 5), representando um crescimento de $20 \%$ em relação a área de 1975.

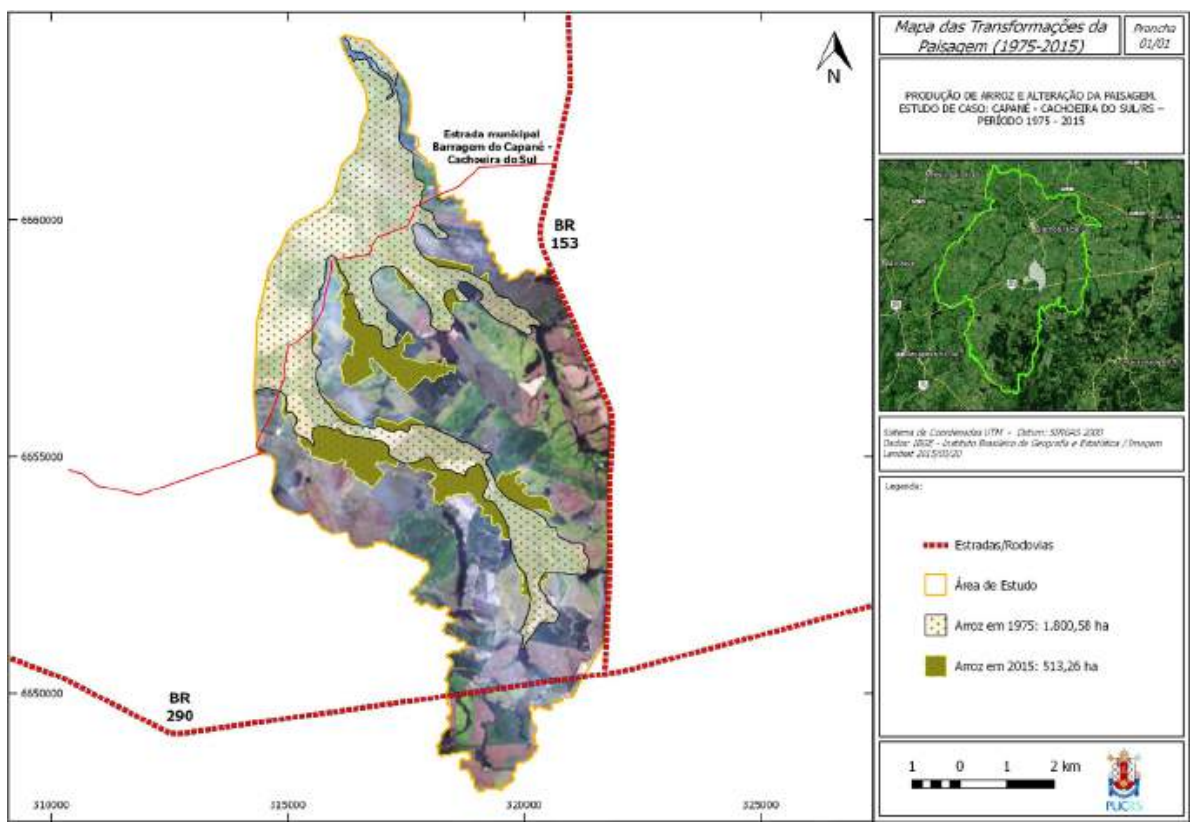

Figura 5 - Mapa da Ocupação das Terras com Cultivo de Arroz em Capané, Cachoeira do Sul/RS (1975-2015).

Em visita à localidade do Capané, foi possível perceber a interação do homem com o meio. Através de registros fotográficos da paisagem e busca de informações com os 
moradores locais, observou-se a harmônica combinação entre as paisagens natural e construída. Verdum (2012) traz como componentes da paisagem natural a vegetação nativa, o solo, os rios, dentre outros, e, como paisagem construída, barragens, estradas, áreas de plantio etc. Na Figura 6, observa-se alguns elementos da ação antrópica na paisagem, como o vertedouro de água da Barragem do Capané (local de saída de água do reservatório), que acaba por abastecer as áreas de plantio de arroz, a estrada vicinal, as próprias lavouras de arroz e áreas de reflorestamento.

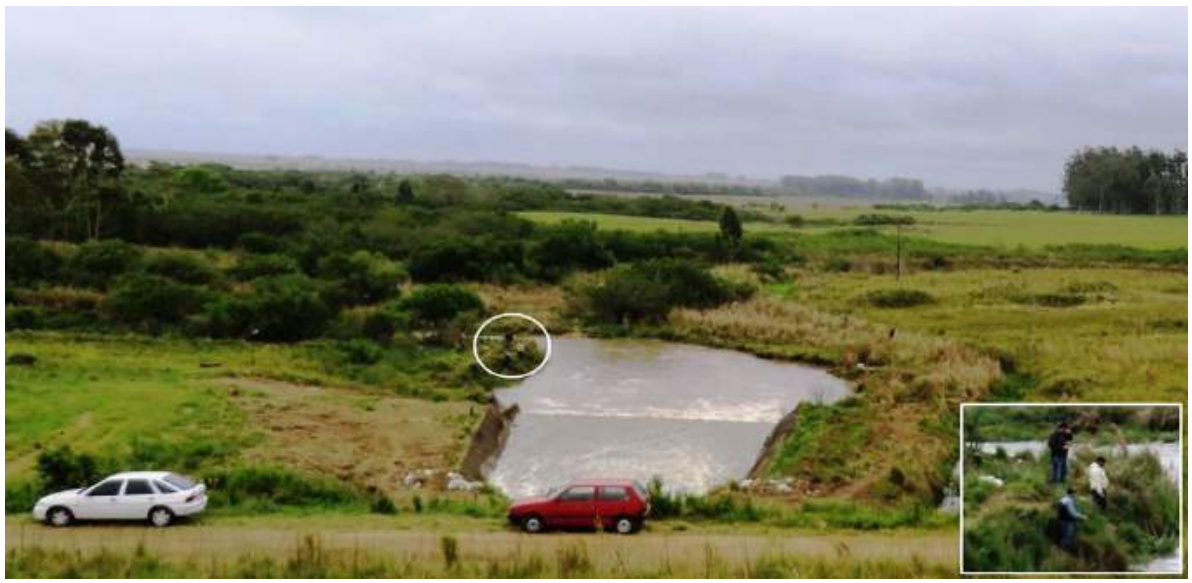

Figura 6 - Local de Saída de Água da Barragem do Capané (Vertedouro).

Além da finalidade de irrigação das lavouras, é possível identificar a presença de pessoas fazendo o uso do vertedouro para atividades de pesca, atribuindo, assim, mais uma função ao local. Deste modo, conforme o pensamento de Verdum (2012, p.18), "cada um de nós, de acordo com a nossa trajetória, nossa consciência, experiência, vê as paisagens de formas diferentes e únicas". Possivelmente, para estas pessoas que estão pescando, este local se traduz como um ambiente de lazer, enquanto para outras, representa uma necessidade para os seus negócios.

Pode se dizer que a paisagem é tudo o que está ao nosso redor, porém não tem uma existência própria, pois ela existe a partir do momento que o sujeito a percebe. Cada um a vê de forma diferente, não só em função do próprio olhar, mas também devido aos seus interesses individuais.

Portanto, ao analisarmos superficialmente a Figura 6, corroboramos com Santos (1994), quando diz que a percepção das áreas, natural e construída, está cada vez mais difícil, uma vez que, dependendo da escala temporal de análise, não será possível distinguir tais alterações da paisagem sem o conhecimento mais aprofundado do local.

Na Figura 7, observa-se uma região de coxilha onde houve inter-relação com instrumentos de trabalho, descritos por Santos (1994) como objetos diversos criados pelo homem para produzir algo. Na imagem é possível a identificação da estocagem de fenos que foram processados mecanicamente e que servirão como alimento na pecuária, também observada nesta cena. Ainda, identificam-se áreas de reflorestamento e pastagem. 


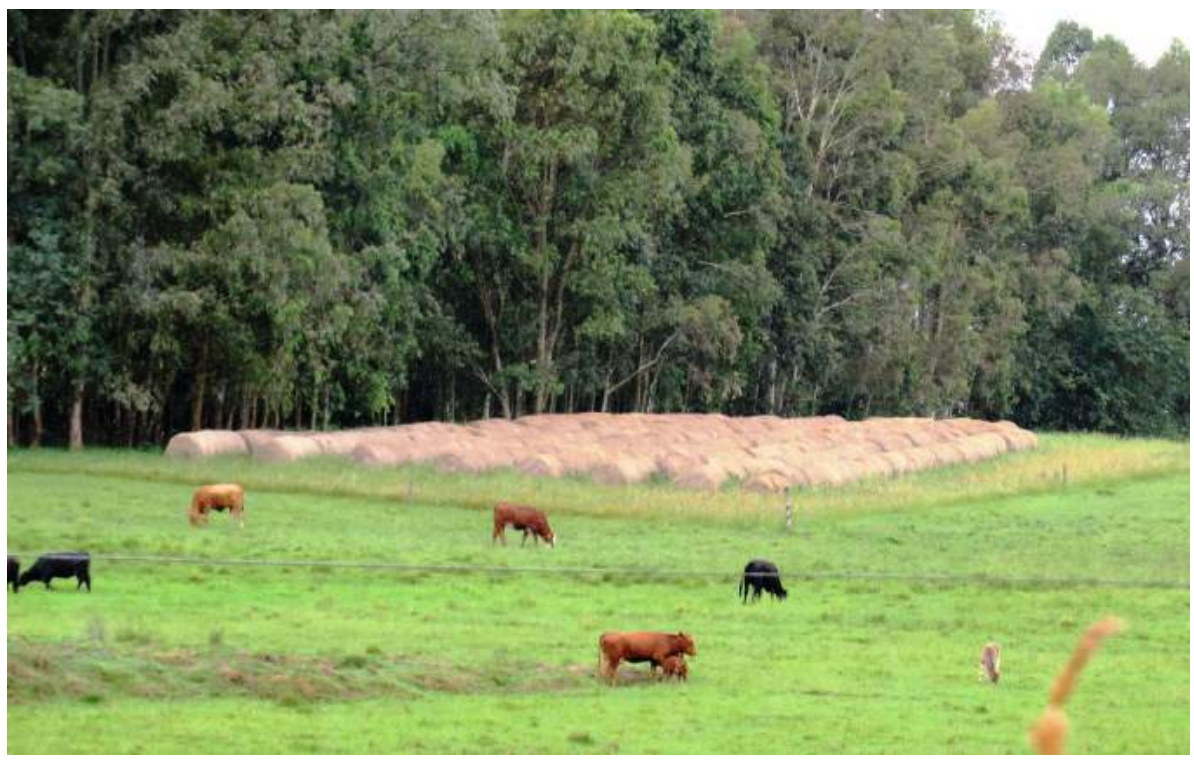

Figura 7 - Áreas de Pastagem, Estocagem de Feno, Pecuária e Reflorestamento.

Conforme visita a campo e análise da Figura 7, a rotação de culturas e/ou integração lavoura-pecuária ${ }^{2}$ faz-se presente na paisagem observada. Consistindo em alternar anualmente espécies vegetais e até mesmo a inserção da pecuária em uma mesma área agrícola, o uso do método mostra a necessidade do agricultor em diversificar sua fonte de renda, uma vez que o cultivo do arroz acontece de forma sazonal.

Por tratar-se de uma cultura desenvolvida em um determinado período do ano, eventos climáticos, quando ocorrem de maneira desproporcional, inviabilizam o processo de plantio e, consequentemente, causam dificuldades financeiras não só para os agricultores, mas também para a economia local. Sendo assim, a integração de culturas em uma mesma área agrícola é um mecanismo constantemente observado na paisagem local.

Além dos registros fotográficos obtidos durante visita à área de estudo, foi possível dialogar com alguns moradores sobre o tema proposto pela pesquisa. Segundo os mesmos, algumas áreas de campo nativo deram lugar às lavouras de arroz. Ainda, citam que parte dessas lavouras foram organizadas através do uso de técnicas de sistematização do solo. Deste modo, ao considerar os avanços tecnológicos no meio rural, neste caso, a localidade do Capané, entende-se que a paisagem se organiza segundo os níveis destes, "na medida em que as exigências de espaço variam em função dos processos próprios a cada produção e ao nível de capital, tecnologia e organização correspondentes." (SANTOS, 1994, p. 66).

A sistematização dos solos de várzea consiste no "processo de adequação da superfície natural do terreno, de forma a transformá-la num plano ou numa superfície curva organizada, de modo que a lavoura passa a ter declividade contínua num mesmo sentido". Neste caso, o arroz é irrigado por inundação, o que consiste em organizar 
espacialmente a paisagem desta região para suprir as necessidades de produção desta cultura (AGEITEC, 2015).

$\mathrm{Na}$ Figura 8, houve o intuito de expor a representação cartográfica das áreas de cultivo do arroz dos anos de 1975 e 2015 e mostrar os pontos dos registros fotográficos realizados durante a visita a campo.

Na fotografia 1 do mapa apresentado na Figura 8, o método de sistematização do terreno é pouco percebido, provavelmente por estar situada em grande parte em área de várzea, local onde a cultura do arroz já está historicamente estabelecida.

Nas fotografias 2 e 3, podem-se observar as áreas que passaram pelo processo de alteração da paisagem através da técnica de sistematização do solo, fazendo com que o relevo respeite uma única cota altimétrica.

Ainda, pode-se analisar que as fotografias 2 e 3 (delimitação mostrada na Figura 8) estão próximas a locais com maior declividade e, dependendo da necessidade de expansão das lavouras e situação econômica dos proprietários atuantes desta região, poderá ocorrer a ampliação das áreas de plantio no futuro, consequentemente, vindo a transformar novamente a paisagem. No entanto, ambos os locais exemplificados na Figura 8 expressam semelhanças na sua paisagem, manifestando as heranças de relações entre homem e natureza, conforme o pensamento de Santos (2006).

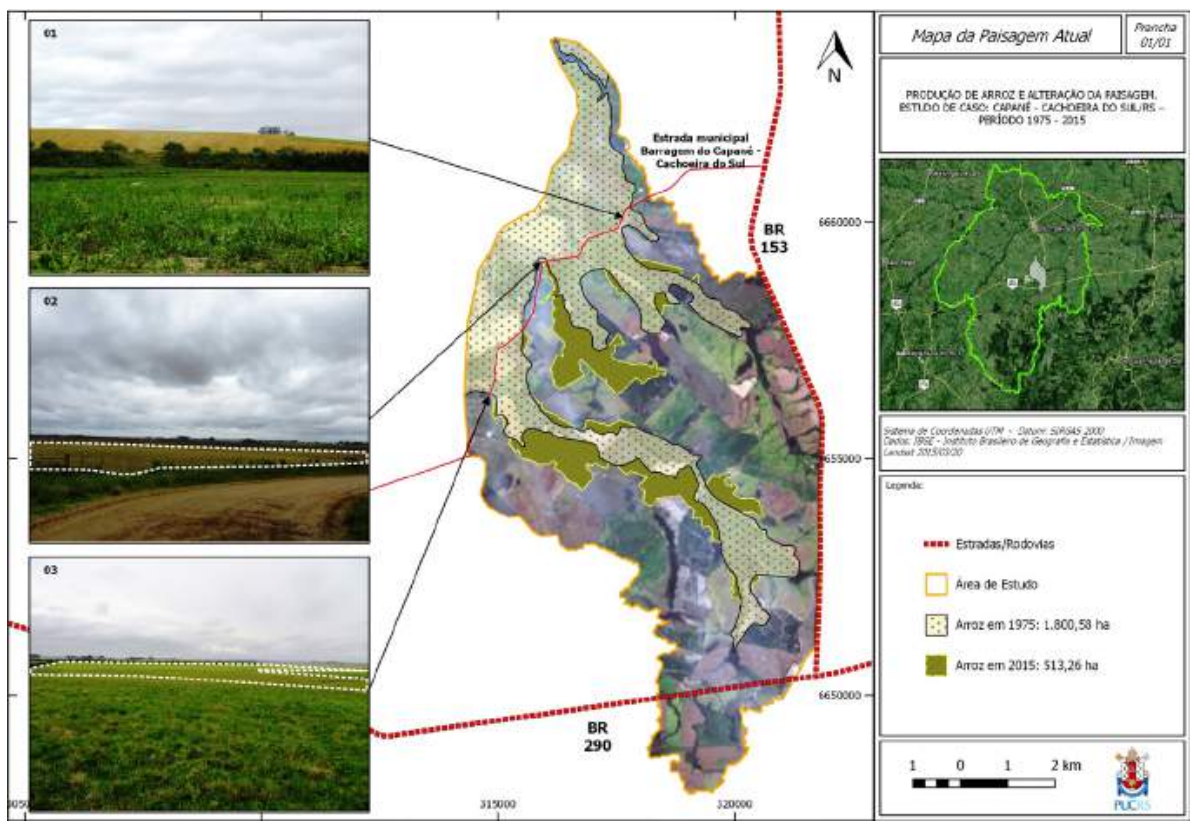

Figura 8 - Mapa da Paisagem Atual.

Localidade do Capané, Cachoeira do Sul/RS. Data: Outubro de 2015.

Segundo moradores do local, certas áreas de várzea próximas aos rios eram compostas por um maior adensamento da vegetação, ou seja, eram mais próximas da sua com- 
posição natural. Sendo assim, cabe salientar que, dentro da paisagem em estudo existem porções do espaço geográfico protegidas por lei, as denominadas Áreas de Preservação Permanente (APPs).

Nesta localidade, no que se refere aos cursos d'água, percebe-se que parte das edificações estão situadas nas áreas com maior altitude, chamadas de coxilhas, o que diminui o risco de inundações nas casas dos moradores. Ao fazer uma análise no banco de dados GIS deste estudo, em algumas situações, observou-se que há uma certa ausência do conhecimento mais aprofundado do local para a escolha da construção das edificações. Porém, segundo os relatos das entrevistas, os moradores possuem consciência dos riscos para suas vidas e moradias, tendo o conhecimento de vida daquele local, obtido através de seus antepassados.

Desta forma, Ab'Saber (2002) salienta que é necessária a busca por harmonizar o desenvolvimento com a adequada postura de proteção ambiental e ecológica, a fim de antecipar impactos futuros que, neste caso, podem ser das mais variadas ordens, inclusive os riscos de inundações para os moradores. No entanto, em Capané, a percepção dos riscos para as pessoas não é estendida às suas áreas de plantio, pois frequentemente foi observado o desrespeito com as APPs, o que de fato, aumenta as possibilidades de impactos ao meio.

Analisando a imagem de satélite e a carta do Exército, junto ao observado nas visitas realizadas na área de estudo, foi possível constatar que, atualmente, parte dos cursos de água sofreram alterações nas suas características naturais, transformando-se em canais de irrigação para as lavouras, conforme observado na Figura 9.

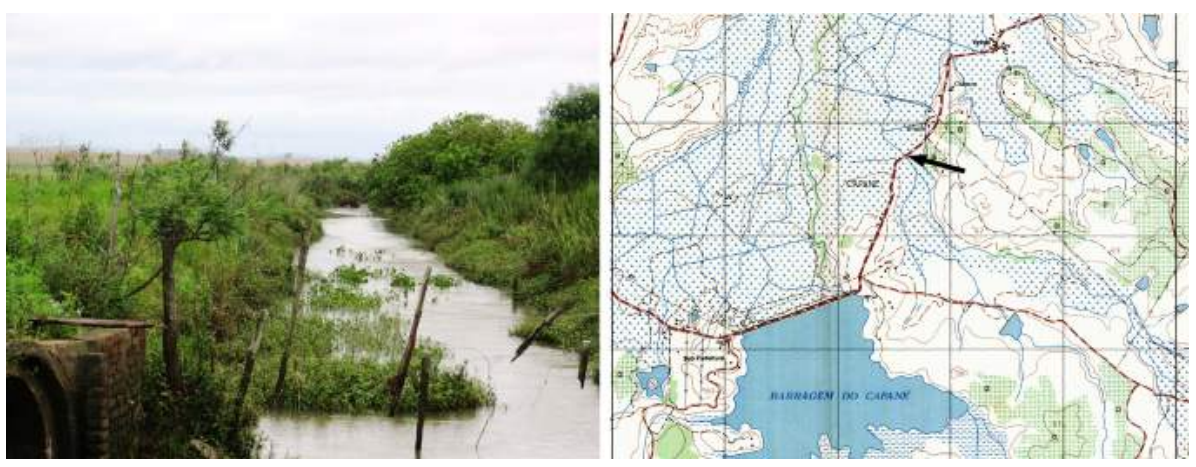

Figura 9 - Curso D’água Utilizado para Irrigação de Lavouras em Capané.

No local de estudo, as áreas protegidas (Áreas de Preservação Permanente) coexistem com a estruturação espacial realizada pela ação antrópica desta região, tanto pelo processo de sistematização das lavouras próximas aos cursos d'água, quanto nos canais de irrigação e benfeitorias presentes nas propriedades, o que de fato, manifesta a participação plena do arranjo homem/natureza, que é o espaço total (AB'SÁBER, 2002).

Correlacionando as áreas de produção da cultura orizícola com dados socioeconômicos disponibilizados pelo IBGE através das sinopses por setores censitários do Censo de 2010, sendo que, o local de estudo abrangeu dois setores censitários, identificou-se 
parcialmente o perfil da população que ali se encontra. Tratando-se do referido local de estudo Capané, no que diz respeito aos domicílios particulares, totalizam 127 domicílios com uma população residente de 259 pessoas, mostrando baixa densidade demográfica. Portanto, pode-se inferir que a população residente por domicílio é em torno de dois indivíduos.

A diferença do predomínio de idade entre homens e mulheres na localidade do Capané acontece da seguinte forma: 51,4 \% são homens, com um predomínio de idade entre 25 a 29 anos e 45 a 49 anos, enquanto 48,6 \% são mulheres com predomínio de idade entre 25 a 29 anos e 40 a 44 anos (IBGE, 2010).

Ao considerar a densidade demográfica, os dados já apresentados e o próprio site da Sinopse por Setores censitários do município, entende-se que parte significativa das pessoas residentes de 60 a 79 anos de idade encontra-se na área urbana. Isso pode ocorrer devido ao fato de o meio urbano dispor de maior conforto e segurança para essas pessoas com a disposição de mercados, farmácias, praças, hospitais, por exemplo. Durante a análise, foi possível perceber que as áreas de plantio dos anos de 1975 e 2015 ficaram entre as altitudes de 35 até 55 metros (Figura 10).
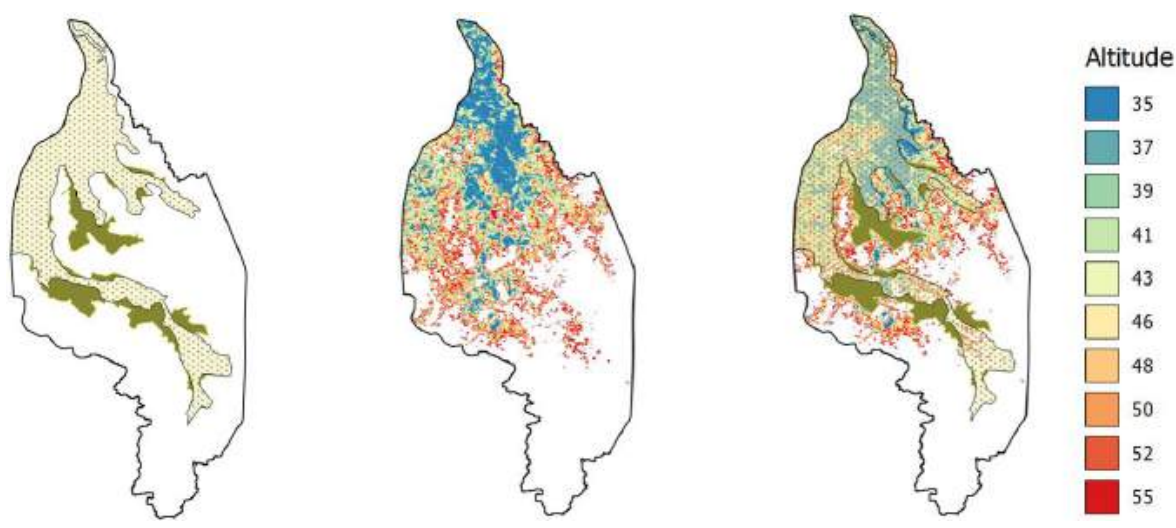

Figura 10 - Áreas de Lavoura de Arroz (1975 e 2015) e Altimetria, Possíveis Locais de Expansão.

Ao analisar a projeção mostrada pela Figura 10, pode-se inferir que as demais áreas que apresentam estas altitudes, especialmente os espaços onde não existem lavouras, poderão futuramente sofrer influência do homem com o plantio do arroz, por meio da técnica de sistematização do solo, pois as áreas de baixas declividades já estão ocupadas pelo cultivo do arroz.

Neste sentido, entende-se que o uso d'água nas lavouras de arroz é utilizado de maneira excessiva. Segundo Mekonnen e Hoekstra (2011), para cada quilo de arroz coIhido no campo é requerido o uso de 1670 litros de água. Entende-se que hoje há uma preocupação cada vez maior com relação aos recursos hídricos, como foi destacado, por exemplo, numa reportagem: "Pesquisas apontam potencial para redução da pegada hídrica nas lavouras de arroz" (Embrapa, 2015). O termo "pegada hídrica" vem de Water 
Footprint Network, nome da organização destinada a resolver a crise de água no mundo, fazendo o uso de água de forma justa e inteligente (WATERFOOTPRINT, 2015).

Segundo o estudo, o projeto para a redução do uso de água nas lavouras de arroz pretende racionalizar o uso da água, mantendo a produtividade. Estima-se que a redução de água possa chegar a 30\% para o estado do Rio Grande do Sul (EMBRAPA, 2015).

Ao interpretar a paisagem da área de estudo, percebe-se a existência das ações e/ou fenômenos da natureza, como intempéries e, ao mesmo tempo, a influência do homem sobre o meio, modificando o terreno, canalizando os cursos d'água de pequeno porte e sistematizando o solo. Percebe-se, ainda, a preocupação em modernizar as lavouras, ajustar os terrenos e, consequentemente, aumentar a produção.

\section{Considerações Finais}

O estudo concebeu um novo olhar e compreensão sobre a paisagem da área de estudo, pois o município de Cachoeira do Sul/RS fica situado na região da depressão central do estado do Rio Grande do Sul, onde está presente um dos principais rios do estado, o Rio Jacuí. Fatores físicos e geográficos, como o índice de precipitação, temperatura e disposição do relevo, propiciam o plantio de diferentes culturas nesta região, sobretudo o arroz.

Diante dos resultados alcançados, pode-se concluir o estabelecimento de relação espacial entre as áreas de plantio de arroz e os dados históricos e socioeconômicos, respondendo ao problema de pesquisa, que é: "investigar como o cultivo de arroz interferiu na paisagem do município de Cachoeira do Sul/RS nos anos de 1975 até 2015".

Respondendo ao objetivo do trabalho, pode-se destacar que nas APPs da microbacia a vegetação nativa sofreu alterações em sua dinâmica natural. Estas alterações ocorreram em função do processo de expansão das lavouras para as áreas próximas aos cursos d'água, coexistindo com a situação atual da área de estudo, em contrariedade à legislação vigente.

Ao mesmo tempo, o diálogo com os moradores trouxe a certeza de que no passado certas áreas de várzea próximas aos rios eram compostas por um maior adensamento da vegetação, semelhantes à sua composição natural, ou seja, à existência da paisagem natural. Desta forma, entende-se que o desenvolvimento das relações sociais e a maneira como o homem produz estão atrelados à natureza. Portanto, o modo de produção atuante implica em uma nova relação com a mesma, para que a degradação dos sistemas naturais não ocorra de maneira desordenada.

Além de analisar as formas concretas e estáticas que integram a paisagem, foi investigado o perfil social relacionado às áreas de plantio e expansão da cultura orizícola, permitindo uma nova leitura desta paisagem.

A busca pelo contexto histórico de Cachoeira do Sul/RS revelou que nesta região a consolidação da cultura orizícola faz-se presente como uma das principais atividades econômicas para o município. Por mais que a cultura do arroz esteja consolidada no referido local de estudo, foi possível perceber a existência de locais com potencial de expansão agrícola no que diz respeito ao cultivo de arroz. No entanto, considerando o 
contexto histórico e os resultados aqui levantados, pode-se dizer que tal expansão ocorrerá paulatinamente na paisagem local.

Em vista do desafio inerente à escala de análise do presente estudo, constatou-se que o resultado obtido no software QGIS e Terrahidro, através dos dados sensor ASTER v2 GDEM para a delimitação da microbacia hidrográfica, mostraram-se satisfatórios a partir das análises realizadas pela pesquisa.

A geografia aliada às técnicas de geoprocessamento e sensoriamento remoto permitiu compreender o processo de expansão das áreas de lavouras de arroz na microbacia, por meio de um conjunto de análises, ao relacionar dados de diversas fontes, tais como imagens de satélites, cartas topográficas, hidrografias, sistema viário, limites municipais e dados socioeconômicos.

A partir dos dados demográficos por setores censitários do Censo de 2010 disponibilizados pelo IBGE, foi possível estabelecer parcialmente uma relação com o perfil da população residente da área de estudo.

Para compreender o contexto que envolveu a expansão das áreas de lavouras de arroz na localidade do Capané, foi necessário recorrer ao entendimento de espaço geográfico, Espaço Total, Paisagem Natural e Construída, Geoprocessamento e Sensoriamento Remoto. Cabe salientar que a leitura perceptiva da paisagem foi fundamental para investigação do problema-pesquisa, pois deve ser descritiva e inventariada, ultrapassando o campo do visível. Sendo assim, os conceitos aqui levantados mostraram-se essenciais para investigação e compreensão do problema de pesquisa.

Levando em consideração os argumentos apresentados, entende-se que a paisagem é alvo de constantes transformações. No que diz respeito à produção do arroz, o cenário agroeconômico interfere diretamente em tais mudanças. As transformações da paisagem ajudam a compreender a dinâmica que envolve o espaço geográfico, pois, ao expressar acontecimentos históricos na paisagem, revelam ao homem um novo olhar e compreensão sobre o meio.

\section{Referências Bibliográficas}

AB'SÁBER, A. N.; MÜLLER-PLANTENBERG, C. (orgs.). Previsão de impactos: o estudo de impacto ambiental no leste, oeste e sul: experiências no Brasil, na Rússia e na Alemanha. São Paulo: Edusp, 2002. 573 p.

AGEITEC - Agência Embrapa de Informação Tecnológica. Integração lavoura e pecuária. Disponível em: <http://www.agencia.cnptia.embrapa.br/gestor/milho/arvore/CONTAG01_4_168200511157.html>. Acesso em: jan. 2017.

. Sistematização do terreno. Disponível em: <http://www.agencia.cnptia.embrapa.br/gestor/arroz/arvore/CONT000fojvokoc02wyiv80bhgp5pn8x03de.html>. Acesso em: nov. 2015.

ATLASRS - Atlas socioeconômico do Rio Grande do Sul. Clima, temperatura e precipitação. Disponível em: <http://www.atlassocioeconomico.rs.gov.br/conteudo.asp?cod_menu_ 
filho=791\&cod_menu=790\&tipo_menu=APRESENTACAO\&cod_conteudo=1332>. Acesso em: set. 2015.

EMBRAPA - Empresa Brasileira de Pesquisa Agropecuária. Pesquisas apontam potencial para redução da pegada hídrica nas lavouras de arroz. Disponível em: <https://www.embrapa.br/web/portal/busca-de-noticias/-/noticia/7388523/pesquisas-apontam-potencial-para-reducao-da-pegada-hidrica-nas-lavouras-de-arroz>. Acesso em: nov. 2015.

FITZ, P. R. Geoprocessamento sem complicação. São Paulo: Oficina de textos, 2008. 159 p.

IBGE - Instituto Brasileiro de Geografia e Estatística. Sinopse por setores censitários. Disponível em: <http://www.censo2010.ibge.gov.br/sinopseporsetores/>. Acesso em: nov. 2015.

IRGA - Instituto Rio Grandense do Arroz. Arroz irrigado: recomendações técnicas da pesquisa para o Sul do Brasil. Disponível em: <http://www.irga.rs.gov.br/ upload/20140724143610boletim_arroz_irrigado_2012.pdf>. Acesso em: nov. 2015.

MEKONNEN, M.M.; HOEKSTRA, A. Y. The green, blue and grey water footprint of crops and derived crop products. Disponível em: <http://temp.waterfootprint.org/Reports/Chapagain-Hoekstra-2011-waterfootprint-rice.pdf>. Acesso em: jan. 2017.

NASA - METI. Advanced Spaceborne Thermal Emission and Reflection Radiometer - ASTER. Disponível em: <http://asterweb.jpl.nasa.gov/>. Acesso em: jan. 2017.

RADAMBRASIL, Projeto. Folha SH.22 Porto Alegre e parte das Folhas SH.21 Uruguaiana e SI.22 Lagoa Mirim: geologia, geomorfologia, pedologia, vegetação, uso potencial da terra / IBGE. Levantamento de Recursos Naturais, v. 33, p. 324. Rio de Janeiro, 1986.

RITZEL, M. R. M.; SCHUH, A. S. Cachoeira do Sul Princesa do Jacuí. Ed. Martins Livreiro, p. 52, 1997.

SANTOS, M. A natureza do espaço: técnica e tempo, razão e emoção. São Paulo: Edusp, 2006. 260 p.

- Metamorfose do espaço habitado, fundamentos teórico e metodológico da geografia. São Paulo: Ed. Mussite, 1994. 124 p.

STEFANO, N. Indústria arrozeira do Rio Grande do Sul: desempenho de mercado. Universidade Federal de Santa Maria (UFSM), 2009. 13p.

USGS - United States Geological Survey. Landsat 8 Data Documentation and Information. Disponível em: <http://landsat.usgs.gov/landsat8.php>. Acesso em: nov. 2015. 
Jonas Milanesi e Tânia Rodrigues Ferrer

VERDUM, R. (org.). Paisagem: leituras, significados e transformação. Editora da UFRGS, 2012. 256 p.

WATERFOOTPRINT. Use the product gallery to find out the volume of water consumed to produce the goods we rely on everyday. Disponível em: <http://waterfootprint.org/en/ resources/interactive-tools/product-gallery/>. Acesso em: nov. 2015.

Recebido em: 20/02/2017

Aceito em: 27/05/2018

${ }^{1}$ S.D.E - Curso d'água Sem Denominação Específica, segundo o Ministério do Exército - Departamento de Engenharia e Comunicações. Carta do Exército de Cachoeira do Sul, Folha SH.22-Y-A-III-1 MI 2984/1.

${ }^{2}$ A integração lavoura-pecuária é a diversificação, rotação, consorciação ou sucessão das atividades agrícolas e pecuárias dentro da propriedade rural de forma planejada, constituindo um mesmo sistema, de tal maneira que há benefícios para ambas (Embrapa, 2015). A Paisagem como Instrumento de Preservação: Reflexões sobre a Agricultura Itinerante em Biguaçu - Santa Catarina - Brasil. 